\title{
Clinical characteristics and organ system involvement in sarcoidosis: comparison of the University of Minnesota Cohort with other cohorts
}

Hok Sreng Te', David M. Perlman ${ }^{1}$, Chetan Shenoy ${ }^{2}$, Daniel J. Steinberger ${ }^{4}$, Rebecca J. Cogswell ${ }^{2}$, Henri Roukoz ${ }^{2}$, Erik J. Peterson ${ }^{3}$, Lin Zhang ${ }^{5}$, Tadashi L. Allen ${ }^{4}$ and Maneesh Bhargava ${ }^{1 *}$ (D)

\begin{abstract}
Background: Sarcoidosis is a systemic granulomatous disease of unknown etiology. Clinical cohort studies of different populations are important to understand the high variability in clinical presentation and disease course of sarcoidosis. The aim of the study is to evaluate clinical characteristics, including organ involvement, pulmonary function tests, and laboratory parameters, in a sarcoidosis cohort at the University of Minnesota. We compare the organ system involvement of this cohort with other available cohorts.
\end{abstract}

Methods: We conducted a retrospective data collection and analysis of 187 subjects with biopsy-proven sarcoidosis seen at a tertiary center. Organ system involvement was determined using the WASOG sarcoidosis organ assessment instrument. Clinical phenotype groups were classified using the Genomic Research in Alpha-1 Antitrypsin Deficiency and Sarcoidosis criteria.

Results: Mean subject age at diagnosis was $45.8 \pm 12.4$, with a higher proportion of males $(55.1 \%)$, and a higher proportion of blacks (17.1\%) compared to the racial distribution of Minnesota residents (5.95\%). The majority (71.1\%) of subjects required anti-inflammatory therapy for at least 1 month. Compared to the A Case Control Etiologic Study of Sarcoidosis cohort, there was a higher frequency of extra-thoracic lymph node (34.2\% vs. 15.2\%), eye (20.9\% vs. $11.8 \%$ ), liver (17.6\% vs. $11.5 \%)$, spleen (20.9\% vs. $6.7 \%)$, musculoskeletal (9.6\% vs. $0.5 \%)$, and cardiac $(10.7 \%$ vs. 2.3\%) involvement in our cohort. A multisystem disease with at least five different organs involved was identified in $13.4 \%$ of subjects. A restrictive physiological pattern was observed in $21.6 \%$ of subjects, followed by an obstructive pattern in $17.3 \%$ and mixed obstructive and restrictive pattern in $2.2 \%$. Almost half (49.2\%) were Scadding stages II/III. Commonly employed disease activity markers, including soluble interleukin-2 receptor and angiotensin-converting enzyme, did not differ between treated and untreated groups.

(Continued on next page)

\footnotetext{
* Correspondence: bharg005@umn.edu

'Division of Pulmonary, Allergy, Critical Care and Sleep Medicine, Department

of Medicine, Univesity of Minnesota Medical School, Minneapolis, USA

Full list of author information is available at the end of the article
}

\section{$\triangle B M C$}

(c) The Author(s). 2020 Open Access This article is licensed under a Creative Commons Attribution 4.0 International License, which permits use, sharing, adaptation, distribution and reproduction in any medium or format, as long as you give appropriate credit to the original author(s) and the source, provide a link to the Creative Commons licence, and indicate if changes were made. The images or other third party material in this article are included in the article's Creative Commons licence, unless indicated otherwise in a credit line to the material. If material is not included in the article's Creative Commons licence and your intended use is not permitted by statutory regulation or exceeds the permitted use, you will need to obtain permission directly from the copyright holder. To view a copy of this licence, visit http://creativecommons.org/licenses/by/4.0/ The Creative Commons Public Domain Dedication waiver (http://creativecommons.org/publicdomain/zero/1.0/) applies to the data made available in this article, unless otherwise stated in a credit line to the data. 
(Continued from previous page)

Conclusions: This cohort features a relatively high frequency of high-risk sarcoidosis phenotypes including cardiac and multiorgan disease. Commonly-utilized serum biomarkers do not identify subpopulations that require or do better with treatment. Findings from this study further highlight the high-variability nature of sarcoidosis and the need for a more reliable biomarker to predict and measure disease severity and outcomes for better clinical management of sarcoidosis patients.

Keywords: Sarcoidosis, Cohort, Clinical characteristics, Organ system involvement, Clinical phenotyping

\section{Background}

Sarcoidosis is a multi-system disease of unknown etiology characterized by the presence of non-caseating granulomas in involved organs [1]. Although lungs, mediastinal and hilar lymph nodes are most commonly involved, sarcoidosis is associated with heterogeneous manifestations, disease severity, and outcomes [1-4]. The incidence of sarcoidosis is at least 45-300/100,000 individuals in the US [5], of both sexes, and all ages and races [1, 6-8]. The annual mortality is $2.8 /$ million people $[3,9]$ and is rising [10] with a more aggressive course and more extrapulmonary involvement reported in black patients [11].

Recently, four high-risk sarcoidosis manifestations were recognized as highly associated with greater morbidity and mortality [12]. These include treatment-resistant pulmonary disease, neuro-sarcoidosis, cardiac sarcoidosis, and multisystem organ involvement. In the US and Europe, respiratory failure is the most common cause of sarcoidosisrelated mortality $[9,10]$. In contrast, Japanese cohorts have a higher incidence of cardiac disease, and cardiac involvement is the most frequent case of death due to sarcoidosis in Japan [13]. Lofgren's syndrome, an acute presentation of sarcoidosis associated with fever, erythema nodosum, arthralgias and mediastinal or hilar adenopathy, is more frequent in Scandinavian countries and is associated with a good prognosis [14]. The heterogeneity in sarcoidosis presents challenges in predicting disease course, optimizing treatments, and establishing a uniform standard for organ involvement assessment.

There is significant geographic variability in sarcoidosis manifestations. The variability in sarcoidosis manifestations could be explained by regional variability in sarcoidosis but also could be due to the tools employed for assessment of organ involvement. A number of reports have used the tool developed by the A Case Control Etiologic Study of Sarcoidosis (ACCESS) investigators [15] to assess disease manifestation [11, 16, 17]. This tool was further modified by the World Association of Sarcoidosis and Other Granulomatous Disorders (WASOG) task force to address additional manifestations and possible organs involved with sarcoidosis. The WASOG sarcoidosis organ assessment instrument classifies organ involvement as "highly probable", "probable", "possible", or "no consensus" [18]. Various other assessment tools for sarcoidosis have been proposed. More recently, the Genomic Research in Alpha-1 Antitrypsin Deficiency and Sarcoidosis (GRADS) study classified clinical phenotypes into nine clinical phenotype groups [19], including efforts to define multiorgan, cardiac defining therapy, and other phenotypes.

Our objective is to describe the clinical characteristics of the sarcoidosis cases seen at the University of Minnesota, and to compare the characteristics of our cohort to the ACCESS and other cohorts. The racial distribution of Minnesota residents includes White (83.75\%), Black or African American (5.95\%), Asian (4.66\%), two or more races (2.81\%), other race (1.74\%), Native American (1.05\%), and Native Hawaiian or Pacific Islander (0.04\%) [20]. A unique feature of the Minnesota population is the substantially higher percentage of residents of Scandinavian origin which may influence the disease manifestations. While only $0.2 \%$ of US population is of Scandinavian origin, up to $1.5 \%$ of Minnesota residents self-report a Scandinavian origin, and we presume that our cohort may have this representation [21].

\section{Methods}

This cohort includes 187 sarcoidosis subjects consented between March 2015 and May 2019 at a tertiary sarcoidosis referral center in Minnesota. The diagnosis of sarcoidosis was made per American Thoracic Society (ATS) statement [1], meeting the following criteria: 1) a compatible clinical and radiologic finding; 2) histological evidence of noncaseating granulomas; and 3) exclusion of other diseases such as infections, common variable immunoglobulin deficiency (CVID), chronic beryllium disease (CBD), and malignancy. Diagnosis dates were determined per biopsy dates and estimated to be June 15th when days and/or months were not available. Subjects without histological evidence were excluded from this cohort. Subjects with a history of malignancy diagnosed within two years prior to or after sarcoidosis were excluded to exclude the possibility of sarcoidlike reactions to malignancies.

We conducted a chart review to collect data on demographics, diagnostics, imaging, past medical history, treatment program, and pulmonary function tests. Racial demographics were collected per patient self-report through the electronic medical record. With limited data, Hispanic whites and non-Hispanic whites were both categorized as "White" in this study. Results from laboratory 
within one year prior to the initial visit were also collected, including angiotensin converting enzyme (ACE), white blood count (WBC) with differential, soluble interleukin-2 receptor (sIL-2R), C-reactive protein (CRP), immunoglobulin G (IgG), albumin, total protein, liver function tests, calcium, parathyroid hormone (PTH), 25-OH vitamin D, and $1,25-\mathrm{DiOH}$ vitamin $\mathrm{D}$. Scadding stage was established using the closest available imaging study - chest $\mathrm{x}$-ray (CXR) and chest CT topogram if CXR was not available - by an expert independent chest radiologist. The treatment groups, organ involvement, and clinical phenotype were assessed based on the characteristics at enrollment and prior history.

In the absence of histological evidence, the organ system involvement was determined using the "highly probable" and "probable" criteria per the WASOG sarcoidosis organ assessment instrument [18]. Per the WASOG instrument, thoracic involvement includes both pulmonary involvement and thoracic lymph node involvement. One modification we made from the instrument was that although arthralgia was listed under "possible" criteria, we included it for bone-joint involvement when it was associated with Lofgren's syndrome. Additionally, small fiber neuropathy with positive skin biopsy findings was included for nervous system involvement. In addition to PET, subjects with abnormal signal intensity on magnetic resonance imaging (MRI) of bone marrow were also included for bone marrow involvement.

We established the clinical phenotype groups using the GRADS criteria [19] with minor modifications. Subjects with Lofgren's syndrome but treated for $>3$ months were nonetheless assigned to Acute Sarcoidosis (Group 7). Untreated or treated subjects who were off treatment for at least one year from the visit date were assigned to the Remitting Disease group (Group 8). Subjects with five or more involved organs including cardiac involvement and on systemic anti-inflammatory therapy without remission (not assigned to Group 8) were assigned to Cardiac Defining Therapy (Group 9) as opposed to Multiorgan Disease (Group 1). We identified unclassifiable cases that did not fit any of the GRADS phenotypes, including Stage 0 treated or untreated and Stage I treated.

We grouped the PFT abnormalities into obstructive, restrictive, or mixed obstructive and restrictive ventilatory defects. Obstructive ventilatory defect was defined using Global Initiative for Chronic Obstructive Lung Disease criteria as forced expiratory volume in $1 \mathrm{~s} \mathrm{(FEV1)} \mathrm{/} \mathrm{forced}$ vital capacity (FVC) ratio (FEV1/FVC) $<70 \%$ and a reduction of FEV1 [22]. Restriction ventilatory defect was defined as FEV1/FVC ratio $\geq 70 \%$ and a reduction in FVC. A mixed obstructive and restrictive pattern was defined as FEV1/FVC ratio $<70 \%$, a decrease in FEV1 and total lung capacity (TLC). To simplify the interpretation, the FEV1, FVC, TLC and diffusing capacity of the lungs for carbon monoxide (DLCO) were considered reduced if they were below $80 \%$ of predicted values.

Statistical analysis was conducted using $\mathrm{R}$ version 3.6.1. Categorical variables were analyzed using Chi-square test or Fisher's exact test when expected values are less than five, while continuous variables were conducted using two-sample Student's t-test and analysis of variance (ANOVA) when more than two groups were compared, with $p<0.05$ considered statistically significant.

\section{Results}

\section{Demographics}

We included 187 consecutive sarcoidosis subjects with histological evidence of noncaseating granulomas and a clinical presentation consistent with sarcoidosis (Table 1). The majority of the subjects were white $(70.6 \%)$ or African American (17.1\%). The mean age at diagnosis was $45.8 \pm 12.4$ years, with no significant difference between males ( $44.7 \pm 12.5$ years) and females $(47.1 \pm 12.1$ years), and whites ( $47.1 \pm 12.6$ years) and blacks ( $43.3 \pm$

Table 1 Demographic characteristics of the cohort $(n=187$ )

\begin{tabular}{ll}
\hline Characteristics & mean \pm SD or $n(\%)$ \\
\hline Age at enrollment (years) & $53.0 \pm 12.6$ \\
Age at diagnosis (years) & $45.8 \pm 12.4$ \\
Sex & \\
Male & $103(55.1 \%)$ \\
Female & $84(44.9 \%)$ \\
Race & \\
White & $132(70.6)$ \\
African American & $32(17.1)$ \\
Asian & $3(1.6)$ \\
American Indian or Alaska Native & $1(0.5)$ \\
Choose not to answer & $19(10.2)$ \\
Body mass index (kg/m $\left.{ }^{2}\right)$ & $31.2 \pm 7.1$ \\
Smoking status & \\
Never & $101(54.0)$ \\
Former & $71(38.0)$ \\
Current & $15(8.0)$ \\
Family history of sarcoidosis & $16(9.0)$ \\
Use of anti-inflammatory agents & \\
Treated $\geq 1$ month & $85.0 \pm 23.5$ \\
Treated < 1 month or never & $133(71.1)$ \\
Fulmonary function tests & $54(28.9)$ \\
FVC (\% predicted) & \\
TLC (\% predicted) & $92.7 \pm 17.5 \pm 26.0$ \\
\hline
\end{tabular}


10.9 years). More than half of the subjects were males (55.1\%). The mean body mass index (BMI) was $31.2 \pm$ $7.1 \mathrm{~kg} / \mathrm{m}^{2}$, with no significant difference between males $\left(31.4 \pm 6.4 \mathrm{~kg} / \mathrm{m}^{2}\right)$ and females $\left(31.0 \pm 7.8 \mathrm{~kg} / \mathrm{m}^{2}\right)$, and Whites $\left(31.6 \pm 6.8 \mathrm{~kg} / \mathrm{m}^{2}\right)$ and Blacks $\left(29.6 \pm 6.4 \mathrm{~kg} / \mathrm{m}^{2}\right)$. The use of anti-inflammatory medications for at least one month for sarcoidosis was present in $71.1 \%$ of subjects. The mean age at diagnosis for the treated group (44.2 \pm 12.0 years) who received immunosuppression for $\geq 1$ month was lower compared to cases $(50.0 \pm 12.4$ years) that were never treated or treated $<1$ month. The treated group also had a higher mean BMI $(32.0 \pm 7.5$ $\mathrm{kg} / \mathrm{m}^{2}$ vs $\left.29.4 \pm 5.7 \mathrm{~kg} / \mathrm{m}^{2}, p=0.01\right)$. Only a minority of the subjects $(9 \%)$ reported a family history of sarcoidosis. Thirty eight percent of subjects were former cigarette smokers, and $8 \%$ were current smokers.

\section{Organ involvement}

Organ involvement was assessed using the WASOG sarcoidosis organ assessment instrument [18]. Thoracic involvement was detected in 184 (98.4\%) subjects by histology or imaging studies with chest $\mathrm{x}$-ray (CXR) and/or CT scan, with the majority of the cases (85.9\%) having histological evidence of noncaseating granulomas (Table 2). Extra-thoracic involvement was observed in $128(68.4 \%)$ subjects, $59(31.6 \%)$ subjects had thoracic involvement only, and $3(1.6 \%)$ subjects had extrathoracic involvement only. Bone and joint involvement were more frequent for whites $(8.2 \%$ vs $0 \%$ for blacks, $p=0.04)$. Otherwise, there was no statistically significant association between each of the organ involvement and sex, race, or treatment group.

Other organs that were commonly involved included extra-thoracic lymph nodes (34.2\%), eye (20.9\%), and spleen (20.9\%). Extra-thoracic adenopathy was detected by imaging in at least two sites, including cervical, supraclavicular, axillary, paraoesophageal, mesenteric, retroperitoneal, portocaval, hepatogastric, paraaortic, porta hepatis, inguinal, or iliac chain node stations; $28.1 \%$ of those with adenopathy underwent biopsy that provided evidence of granulomatous lymphadenitis. Among those with ocular disease, uveitis (61.5\%) and lacrimal gland enlargement (18.0\%) were the primary manifestations. In cases with splenic involvement, splenomegaly was present in 12 (30.8\%), and splenic lesions were detected in $28(71.8 \%)$ by imaging studies. In five subjects,

Table 2 Organ involvement and histological evidence indicating subjects with evidence of noncaseating granulomas

\begin{tabular}{|c|c|c|c|c|c|}
\hline \multirow[t]{2}{*}{ Characteristics } & \multicolumn{2}{|c|}{ Organ Involvement per WASOG Tool } & \multicolumn{3}{|c|}{ Histological Evidence } \\
\hline & $\mathrm{n} / 187$ & $\%$ & $95 \% \mathrm{Cl}$ & $n$ /total & $\%$ \\
\hline Lung & 184 & 98.4 & $95.4-99.7$ & $158 / 184$ & 85.9 \\
\hline Skin & 27 & 14.4 & $9.7-20.3$ & $22 / 27$ & 81.5 \\
\hline Liver & 33 & 17.6 & $12.5-23.9$ & $12 / 33$ & 36.4 \\
\hline Eye & 39 & 20.9 & $15.3-27.4$ & $5 / 39$ & 12.8 \\
\hline Spleen & 39 & 20.9 & $15.3-27.4$ & $2 / 39$ & 5.1 \\
\hline Salivary Gland & 4 & 2.1 & $0.6-5.4$ & $1 / 4$ & 25.0 \\
\hline ENT & 4 & 2.1 & $0.6-5.4$ & $3 / 4$ & 75.0 \\
\hline Calcium-VitD & 10 & 5.3 & $2.6-9.6$ & $0 / 10^{\mathrm{a}}$ & 0.0 \\
\hline Bone-Joint & $18^{\mathrm{b}}$ & 9.6 & $5.8-14.8$ & $3 / 18$ & 16.7 \\
\hline Bone Marrow & 6 & 3.2 & $1.2-6.9$ & $4 / 6$ & 66.7 \\
\hline Muscle & 2 & 1.1 & $0.1-3.8$ & $1 / 2$ & 50.0 \\
\hline Extra-Thoracic Lymph Node & 64 & 34.2 & $27.5-41.5$ & $18 / 64$ & 28.1 \\
\hline Kidney & 2 & 1.1 & $0.1-3.8$ & $2 / 2$ & 100.0 \\
\hline Nervous System & 14 & 7.5 & $4.1-12.2$ & $1 / 14^{c}$ & 7.1 \\
\hline Cardiac & 20 & 10.7 & $6.7-16.0$ & $3 / 20$ & 15.0 \\
\hline Other Organs & 9 & 4.8 & $2.2-8.9$ & $6 / 9$ & 66.7 \\
\hline Testis & 3 & 1.6 & $0.3-4.6$ & $2 / 3$ & 66.7 \\
\hline Large intestine & 1 & 0.5 & $0.0-2.9$ & $1 / 1$ & 100.0 \\
\hline Stomach & 2 & 1.1 & $0.1-3.8$ & $2 / 2$ & 100.0 \\
\hline Thyroid & 2 & 1.1 & $0.1-3.8$ & $0 / 2$ & 0.0 \\
\hline Appendix & 1 & 0.5 & $0.0-2.9$ & $1 / 1$ & 100.0 \\
\hline
\end{tabular}

${ }^{\mathrm{a}} 10$ subjects with evidence of calcium stones by stone analysis for calcium-vitD involvement

${ }^{b} 4$ subjects with arthralgia associated with Lofgren's syndrome was included for bone-joint involvement

${ }^{c} 3$ subjects with evidence of small fiber neuropathy by skin biopsy for nervous system involvement 
splenomegaly was secondary to portal hypertension from non-alcoholic steatohepatitis (NASH), and these cases were not considered to have sarcoidosis splenic involvement as there was an alternative explanation for the splenomegaly. The majority of subjects (67.9\%) had more than one organ involved (Table 3). Multiorgan involvement (at least five different organs involved) was identified in $13.4 \%$ of subjects. The mean number of organs involved was higher in treated vs. untreated cases in our cohort (2.7 vs 2.1, $p=0.004)$. Otherwise, there was no significant difference in the mean number of organs involved across gender and racial groups.

High-risk sarcoidosis with cardiac or neurologic involvement was observed in $20(10.7 \%)$ and 14 (7.5\%) subjects, respectively. Among subjects with cardiac involvement, three had endomyocardial biopsies demonstrating granulomatous inflammation; eight had a history of ventricular tachycardia and/or high-degree atrioventricular (AV) block such as Morbitz type II or complete heart block found in five subjects; ten had left ventricular ejection fraction below $50 \%$. Nine patients received automatic implantable cardioverter defibrillators and two cases had pacemaker implantation. Advanced cardiac imaging was abnormal with suggestion of myocardial involvement in 16 cases. 18F-fluorodeoxyglucose (FDG) positron emission tomography (PET) performed with a cardiac protocol demonstrated abnormal uptake in 13 subjects, while late gadolinium enhancement (LGE) on cardiac MRI was detected in 9 subjects [23]. One subject underwent heart transplant. For nervous system involvement, three subjects had small fiber neuropathy, followed by three pituitary, two meninges, two spinal cord, one cranial nerve, one white matter, one sensory hearing loss, and one craniofacial with peripheral neuropathy. Two subjects had both cardiac and neurological involvement.

\section{Pulmonary function tests and Scadding stage}

Pulmonary function tests were available for 185 subjects. Normal pulmonary function tests were observed in 109

Table 3 Number of organs involved in each subject

\begin{tabular}{lll}
\hline $\begin{array}{l}\text { Number } \\
\text { of } \\
\text { organs }\end{array}$ & Cases \% & $\%$ \\
\cline { 2 - 3 } 1 & $n$ & 32.1 \\
2 & 60 & 26.7 \\
3 & 50 & 18.7 \\
4 & 35 & 9.1 \\
5 & 17 & 7.5 \\
6 & 14 & 3.7 \\
7 & 7 & 1.1 \\
8 & 2 & 1.1 \\
\hline
\end{tabular}

(58.9\%) subjects, a restrictive pattern in 40 subjects (21.6\%), an obstructive pattern in 32 subjects (17.3\%), and mixed obstructive and restrictive pattern in $4(2.2 \%)$ subjects. For FVC, the median and 25th percentile were $88 \%$ predicted and $72 \%$ predicted, respectively. For FEV1, they were $84 \%$ predicted and $67 \%$ predicted, and for DLCO, they were $93 \%$ predicted and $75 \%$ predicted, respectively. Lung volumes were available for 129 subjects, and the median and 25th percentile of TLC were $95 \%$ predicted and $82 \%$ predicted, respectively. Twentynine $(22.5 \%)$ cases had decreased TLC (below $80 \%$ predicted), and $22(17.1 \%)$ had restriction on spirometry and decreased TLC. Decreased TLC with normal spirometry was seen in only 4 (3.1\%) cases. Fifty-five (30.4\%) subjects had reduced DLCO, while 12 (6.6\%) had reduced DLCO with normal spirometry. Eighteen (14.0\%) subjects had abnormal DLCO with normal TLC, and 4 (2.2\%) had an isolated decrease in DLCO with normal spirometry and lung volumes. Black subjects had lower mean FVC, FEV1, and DCLO than white subjects $(p<$ 0.001) (Fig. 1, panel a, b, d). Likewise, subjects treated with anti-inflammatory medications for at least $\geq 1$ month had lower mean FVC, FEV1, and DLCO $(p<0.001)$, and lower FEV1/FVC ratio $(p=0.006)$ compared to untreated subjects (Fig. 1, panel e, f, g, h).

Ninety-two (49.2\%) cases had parenchymal lung involvement with Scadding stage II or III disease. Seventy cases $(37.4 \%)$ had Scadding stage 0 disease, and $2.1 \%$ had primarily fibrotic stage IV (Table 4 ). Difference in the mean FVC, FEV1, FEV1/FVC and DLCO were observed based on Scadding stage $(p<0.001$, Fig. 2). The mean FVC was $92 \pm 19 \%$ for stage 0 , $95 \pm 17 \%$ for stage I, $80 \pm 20$ for stage II, $79 \pm 21$ for stage III, and $48 \pm 18$ for stage IV. The mean FVC was lower in stage IV disease compared to other Scadding stages, suggesting a restrictive pattern in these cases. Cases with parenchymal involvement (stage II or III) had lower mean FVC than those without parenchymal disease (stage 0 or I). The mean DLCO was $97 \pm 23 \%$ for stage $0,99 \pm 28 \%$ for stage I, $86 \pm 21 \%$ for stage II, $81 \pm 26 \%$ for stage III, and $39 \pm$ $19 \%$ for stage IV. Similar to FVC, the mean DLCO was lower for the Scadding stage IV cases compared to those of other Scadding stages, and although in normal range, the mean DLCO of stage II and II combined was lower than cases with no parenchymal lung disease. The mean FEV1 was $90 \pm 20$ for stage 0 , $94 \pm 13$ for stage I, $69 \pm 21$ for stage II, $74 \pm 22$ for stage III, and $31 \pm 10$ for stage IV. Of the 32 cases with obstructive disease, the mean FEV1 was $69 \pm 10$ for stage $0(n=5), 53 \pm 18$ for stage II $(n=15), 55 \pm$ 14 for stage III $(n=10)$, and $27 \pm 6$ for stage IV $(n=$ 2 ). No subject with obstructive pattern had stage I disease. 

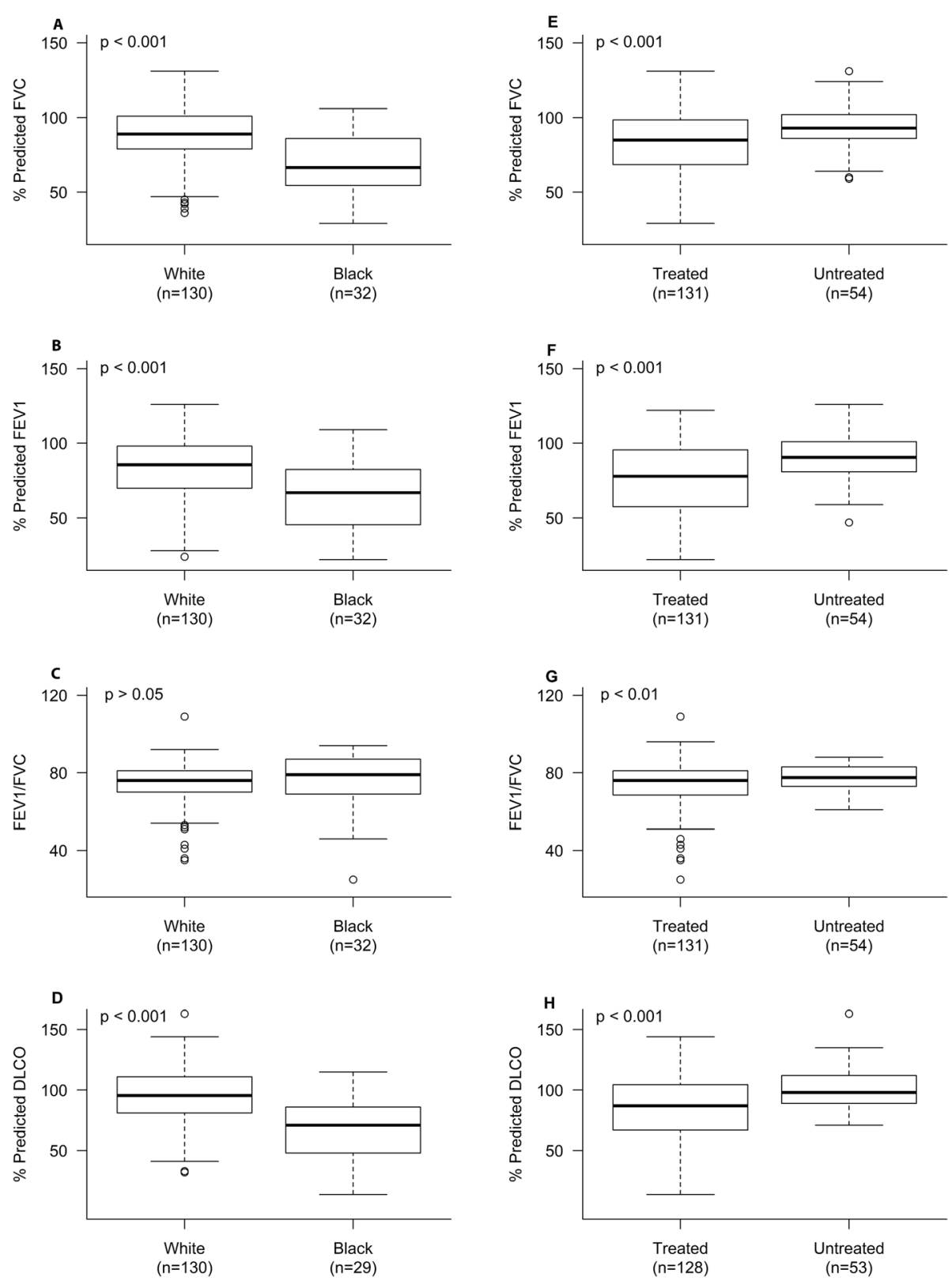

Fig. 1 Percent predicted FVC, \% predicted FEV1, FEV1/FVC ratio, and \% predicted DLCO between treated and untreated groups, and whites and blacks. A statistically significant difference at $p<0.001$ in the FVC, FEV1, and DLCO was observed between treated and untreated groups, and whites and blacks. For FEV1/FVC ratio, a significant difference at $p<0.01$ was only observed between treated and untreated groups

\section{Treatment groups}

The majority $(71.1 \%)$ of subjects reported treatment for at least 1 month for sarcoidosis. Systemic antiinflammatory agents for greater than three months were needed in $123(65.8 \%)$ cases, and only 22 (11.8\%) were off therapy at one-year anniversary of start treatment (Table 5). Prednisone was the first agent for a majority $(70.1 \%)$ of the cases, and methotrexate and Imuran were used in 59 (31.6\%) and 9 $(4.8 \%)$ cases respectively. Fourteen cases received infliximab with a preferred dose of $5 \mathrm{mg} / \mathrm{kg}$ for induction (0,2 and 4 weeks) and a maintenance dose given every 4 weeks. Solumedrol $1 \mathrm{~g}$ once a month was used in cases with cardiac disease and when there were adverse effects or intolerance of conventional oral or biologic agents. $31.0 \%$ of subjects were treated with only one anti-inflammatory agent, while $23.5 \%$ were treated with two and $10.7 \%$ with three anti-inflammatory agents (Table 6) for management of sarcoidosis over the duration of illness. 
Table 4 Demographics by Scadding stage

\begin{tabular}{|c|c|c|c|c|c|c|}
\hline Stage & 0 & 1 & ॥ & III & IV & $p$ value \\
\hline Number of subjects & $70(37.4 \%)$ & $21(11.2 \%)$ & $47(25.1 \%)$ & $45(24.1 \%)$ & $4(2.1 \%)$ & \\
\hline Age at enrollment (years) & $52.5 \pm 12.2$ & $49.0 \pm 12.5$ & $53.9 \pm 13.2$ & $54.5 \pm 12.7$ & $53.5 \pm 9.7$ & 0.55 \\
\hline Age at diagnosis (years) & $47.1 \pm 12.3$ & $43.2 \pm 11.7$ & $45.9 \pm 13.9$ & $45.0 \pm 11.6$ & $41.5 \pm 4.2$ & 0.67 \\
\hline BMI $\left(\mathrm{kg} / \mathrm{m}^{2}\right)$ & $31.5 \pm 7.9$ & $30.3 \pm 5.0$ & $31.2 \pm 5.2$ & $31.6 \pm 8.5$ & $29.3 \pm 4.1$ & 0.94 \\
\hline \multicolumn{7}{|l|}{ Sex } \\
\hline Male & $30(16.0)$ & $12(6.4)$ & $31(16.6)$ & $26(13.9)$ & $4(2.1)$ & \multirow[t]{2}{*}{0.04} \\
\hline Female & $40(21.4)$ & $9(4.8)$ & $16(8.6)$ & $19(10.2)$ & $0(0.0)$ & \\
\hline \multicolumn{7}{|l|}{ Race } \\
\hline White & $52(27.8)$ & $12(6.4)$ & $38(20.3)$ & $29(15.5)$ & $1(0.5)$ & \multirow[t]{5}{*}{0.04} \\
\hline Black & $9(4.8)$ & $3(1.6)$ & $7(3.7)$ & $11(5.9)$ & $2(1.1)$ & \\
\hline Asian & $3(1.6)$ & $0(0.0)$ & $0(0.0)$ & $0(0.0)$ & $0(0.0)$ & \\
\hline American Indian or Alaska Native & $1(0.5)$ & $0(0.0)$ & $0(0.0)$ & $0(0.0)$ & $0(0.0)$ & \\
\hline Choose not to answer & $5(2.7)$ & $6(3.2)$ & $2(1.1)$ & $5(2.7)$ & $1(0.5)$ & \\
\hline \multicolumn{7}{|l|}{ Smoking status } \\
\hline Current & $6(3.2)$ & $2(1.1)$ & $3(1.6)$ & $3(1.6)$ & $1(0.5)$ & \multirow[t]{3}{*}{0.27} \\
\hline Former & $28(15.0)$ & $3(1.6)$ & $18(9.6)$ & $20(10.7)$ & $2(1.1)$ & \\
\hline Never & $36(19.3)$ & $16(8.6)$ & $26(13.9)$ & $22(11.8)$ & $1(0.5)$ & \\
\hline
\end{tabular}

\section{Clinical phenotypes per GRADS}

Clinical phenotypes were determined using the GRADS study criteria. Cases with remitting disease, i.e., subjects who were never treated or were off treatment for greater than 12 months, were the largest group $(n=45$ [24.1\%]) in this cohort (Table 7). Of those classified into Group 8 , five subjects had multiorgan involvement while four subjects had cardiac involvement. We then evaluated the proportion of cases with parenchymal disease based on GRADS phenotyping. Forty-four (23.5\%) subjects were
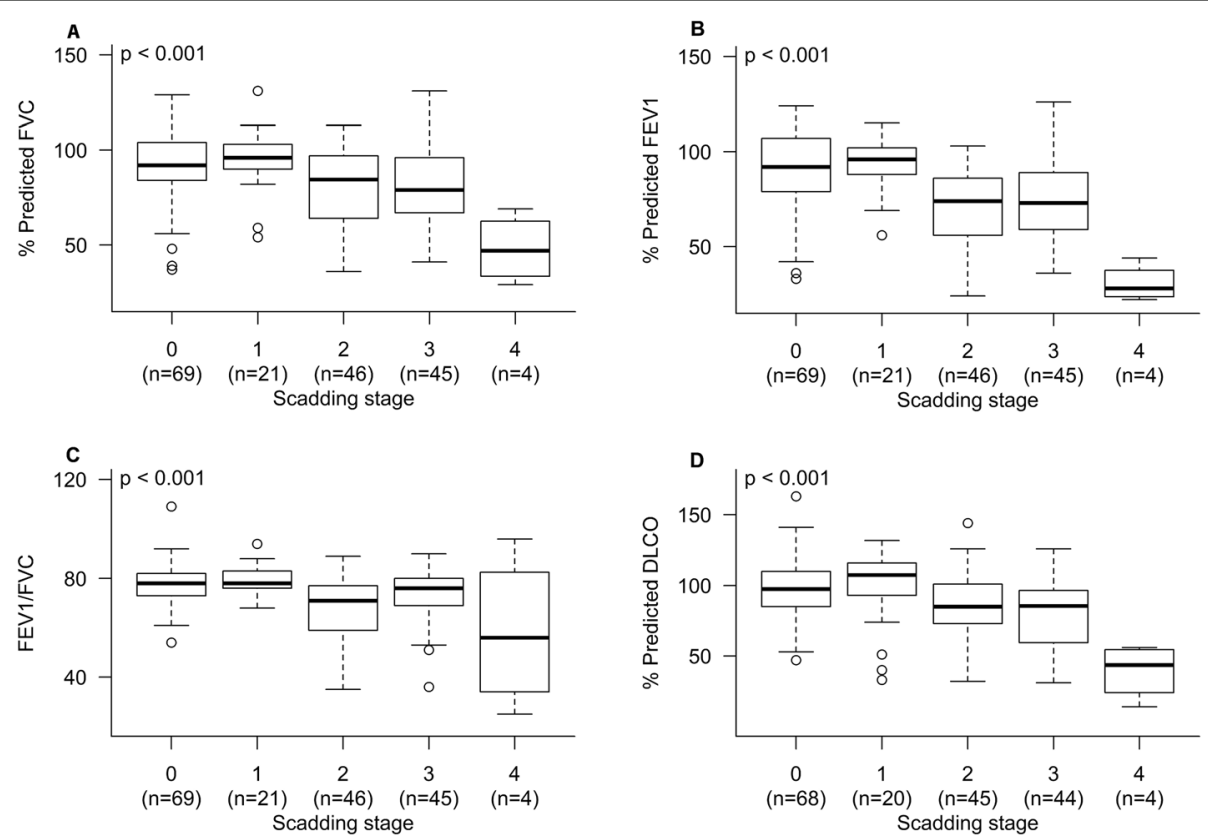

Fig. 2 Percent predicted FVC, \% predicted FEV1, FEV1/FVC ratio, and \% predicted DLCO (not corrected for hemoglobin). The FVC, FEV1, FEV1/FVC ratio, and DLCO were different by Scadding stage, with $p<0.001$. Further post hoc test with Tukey's HSD shows significant difference in FVC and FEV1 between Scadding stages 0 and 2, 0 and 3, 0 and 4, 1 and 2, 1 and 3, 1 and 4, 2 and 4, and 3 and 4. For FEV1/FVC ratio, a significant difference was observed between stages 0 and 2, 0 and 4, 1 and 2, 1 and 4, and 3 and 4. Meanwhile, for DLCO, a significant difference was found between stages 0 and 3,0 and 4, 1 and 4, 2 and 4, and 3 and 4 
Table $\mathbf{5}$ Treatment groups by duration and agents

\begin{tabular}{lll}
\hline Treatment Groups & $n$ & $\%$ \\
\hline Treated $<1$ month or never & 54 & 28.9 \\
Treatment $\geq 1$ month & 133 & 71.1 \\
Treatment $>3$ months & 123 & 65.8 \\
Off treatment $\geq 12$ months & 22 & 11.8 \\
Prednisone & 131 & 70.1 \\
Methylprednisolone & 13 & 7.0 \\
Methotrexate & 59 & 31.6 \\
Azathioprine & 9 & 4.8 \\
Mycophenolic acid & 13 & 7.0 \\
Hydroxychloroquine & 16 & 8.6 \\
Infliximab & 14 & 7.5 \\
\hline
\end{tabular}

classified into Group 3 Stage II-III treated, with 23 (12.3\%) subjects classified into Group 4 Stage II-III untreated. Meanwhile, only 1.1 and $0.5 \%$ of subjects were classified into Group 5 Stage IV treated and Group 6 Stage IV untreated, respectively. A substantial number of cases were not classifiable based on GRADS phenotyping ( $n=37[19.8 \%]$ ), including $4.3 \%$ with Stage I who were treated, $14.4 \%$ with Stage 0 treated, and $1.1 \%$ with Stage 0 untreated. Some of the cases who met criteria for Group 1 (multiorgan disease) or Group 9 (cardiac defining therapy) were not included for the respective groups if they met criteria for remitting disease. For instance, while 25 subjects had multiorgan involvement, only 16 of them were classified into Group 1 Multiorgan since six of them were classified into Group 8 Remitting and three of them were classified into Group 9 Cardiac defining therapy. Likewise, while 20 subjects had cardiac involvement, only seven of them who were treated for cardiac involvement and not remitting were classified into Group 9 Cardiac defining therapy.

\section{Laboratory values}

The sarcoidosis relevant laboratory studies for this cohort are shown in Table 8. A higher WBC count $(p=$ $0.003)$, and lower albumin $(p=0.04)$ was seen in cases who were treated. White cases had lower IgG $(p=0.01)$, higher albumin $(p=0.01)$, and lower total protein levels

Table 6 Number of immunosuppression agents used in each subject

\begin{tabular}{ll}
\hline Number of agents used & $n(\%)$ \\
\hline 0 & $54(28.9 \%)$ \\
1 & $58(31.0 \%)$ \\
2 & $44(23.5 \%)$ \\
3 & $20(10.7 \%)$ \\
4 & $7(3.7 \%)$ \\
5 & $4(2.1 \%)$ \\
\hline
\end{tabular}

Table 7 Clinical phenotype study groups per GRADS

\begin{tabular}{lll}
\hline Clinical Phenotype Study Groups & $n$ & $\%$ \\
\hline Group 1: Multiorgan & 16 & 8.6 \\
Group 2: Nonacute, Stage I, untreated & 8 & 4.3 \\
Group 3: Stage II-III, treated & 44 & 23.5 \\
Group 4: Stage II-III, untreated & 23 & 12.3 \\
Group 5: Stage IV, treated & 2 & 1.1 \\
Group 6: Stage IV, untreated & 1 & 0.5 \\
Group 7: Acute sarcoidosis & 4 & 2.1 \\
Group 8: Remitting & 45 & 24.1 \\
Group 9: Cardiac defining therapy & 7 & 3.7 \\
Unclassifiable per GRADS & 37 & 19.8 \\
Stage 1, treated & 8 & 4.3 \\
Stage 0, treated & 27 & 14.4 \\
Stage 0, untreated & 2 & 1.1 \\
\hline
\end{tabular}

( $p=0.002)$ compared to blacks. No significant difference between treated and untreated groups, and between whites and blacks was found for ACE, percent lymphocytes, soluble IL2 receptor, CRP, total bilirubin, alkaline phosphatase, alanine aminotransferase, aspartate aminotransferase, calcium, parathyroid hormone, 25-OH Vitamin D, and 1,25 Di OH Vitamin D.

\section{Discussion}

Our cohort has similarities and crucial differences compared to previously described cohorts (Table 9). This cohort is primarily composed of cases from upper Midwest and has a higher proportion of blacks and lower proportion of whites compared to the racial distribution of Minnesota residents. With respect to the ACCESS cohort, the age at diagnosis in our cohort was similar, but we observed a higher proportion of males and a lower proportion of black subjects in our cohort. We also observed a higher proportion of extra-thoracic lymph node, eye, liver, spleen, and bone-joint involvement. Other cohorts also reported similarities and differences compared to the ACCESS cohort. A cohort of 166 sarcoidosis cases in Israel was older [17]. Similar to ACCESS cases, more patients in the Israeli cohort were females, and the majority of patients had lung involvement. However, fewer sarcoidosis cases in this cohort had extra thoracic lymph node, liver, CNS, and joints involvement. A small cohort of 21 cases form Mexico was different than the ACCESS cohort with a lower proportion of women and lower median age [16]. This group had more frequent skin and bone marrow involvement and less frequent pulmonary involvement. In contrast, a cohort from the University of California [24] found a higher proportion of cases with neurologic involvement, and another cohort in 


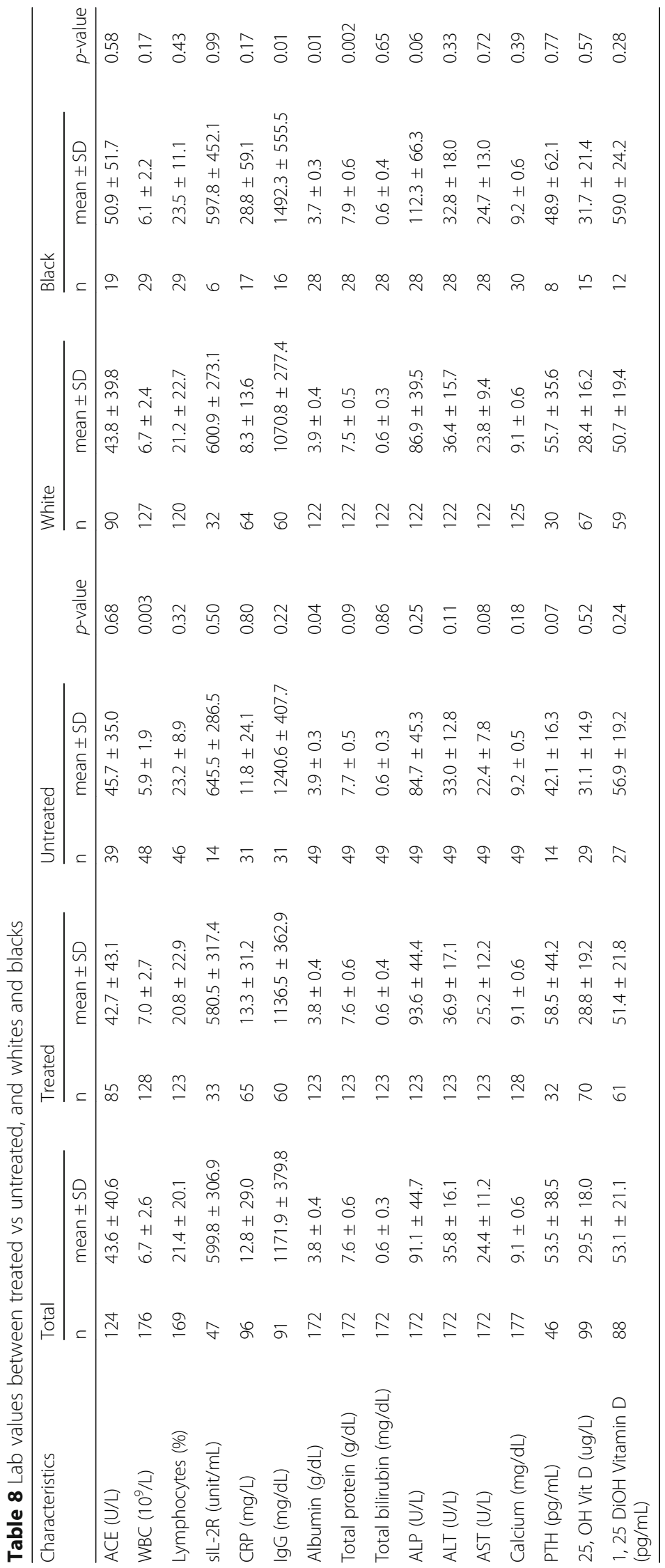


Table 9 Demographics and organ involvement characteristics of various cohorts

\begin{tabular}{|c|c|c|c|c|c|c|}
\hline Characteristics & $\begin{array}{l}\text { UMN } \\
(n=187)\end{array}$ & $\begin{array}{l}\text { ACCESS } \\
(n=736)\end{array}$ & Israel $(n=166)$ & $\begin{array}{l}\text { Mexico City } \\
(n=21)\end{array}$ & $\begin{array}{l}\text { UCSF } \\
(n=126)\end{array}$ & $\begin{array}{l}\text { Olmsted County } \\
(n=N A)\end{array}$ \\
\hline Mean age \pm SD (years) & $45.8 \pm 12.4^{a}$ & $\begin{array}{l}(46 \%<40 \mathrm{yr} \text { old } \\
54 \% \geq 40 \mathrm{yr} \text { old })^{\mathrm{a}}\end{array}$ & $62 \pm 14$ & NA & $50 \pm 12^{b}$ & NA \\
\hline Median age (years) & $45(22-75)^{a}$ & $42.1(18-83)^{\mathrm{a}}$ & $63(26-94)$ & $31(18-72)^{a}$ & $51(30-76)^{\mathrm{b}}$ & NA \\
\hline Male, $n(\%)$ & $103(55.1)$ & $268(36.4)$ & $54(32.5)$ & $10(47.6)$ & $49(39)$ & NA \\
\hline Female, $n(\%)$ & $84(44.9)$ & $468(63.6)$ & $112(67.5)$ & $11(52.4)$ & $77(61)$ & NA \\
\hline White, $n$ (\%) & $132(70.6)$ & $393(53.4)$ & NA & NA & $97(77)$ & NA \\
\hline Black, n (\%) & $32(17.1)$ & $325(44.2)$ & NA & NA & $18(14)$ & NA \\
\hline Other, $n(\%)$ & $23(12.3)$ & $18(2.4)$ & $\begin{array}{l}\text { Jew: } 111(67) \\
\text { Arab: } 51(31) \\
\text { Ethiopian } 4 \text { (2) }\end{array}$ & NA & $11(9)$ & NA \\
\hline Lungs, $n$ (\%) & $184(98.4)$ & $699(95.0)$ & $151(91.0)$ & $14(66.6)$ & NA & $97 \%$ \\
\hline Skinc, n (\%) & $27(14.4)$ & $178(24.2)$ & $5(3.0)$ & $9(42.8)$ & NA & $18 \%$ \\
\hline $\begin{array}{l}\text { Non-thoracic lymph } \\
\text { node, } n(\%)\end{array}$ & $64(34.2)$ & $112(15.2)$ & $5(3.0)$ & $4(19.0)$ & NA & $3 \%$ \\
\hline Eye, $n(\%)$ & 39 (20.9) & 87 (11.8) & $6(3.6)$ & $4(19.0)$ & NA & $7 \%$ \\
\hline Liver, n (\%) & $33(17.6)$ & 85 (11.5) & $6(3.6)$ & $4(19)$ & NA & $6 \%$ \\
\hline Spleen, $n$ (\%) & 39 (20.9) & $49(6.7)$ & $6(3.6)$ & $0(0.0)$ & NA & $4 \%$ \\
\hline Neurologic, n (\%) & $14(7.5)$ & $34(4.6)$ & $12(7.2)$ & $0(0.0)$ & $23(18.3 \%)$ & $3 \%$ \\
\hline Parotid/salivary, n (\%) & $4(2.1)$ & $29(3.9)$ & $0(0.0)$ & $1(4.7)$ & NA & NA \\
\hline Bone marrow, $n(\%)$ & $6(3.2)$ & $29(3.9)$ & $1(0.6)$ & $5(23.8)$ & NA & NA \\
\hline Calcium, $n$ (\%) & $10(5.3)$ & $27(3.7)$ & $1(0.6)$ & $1(4.7)$ & NA & NA \\
\hline ENT, $n(\%)$ & $4(2.1)$ & $22(3.0)$ & $0(0.0)$ & $1(4.7)$ & NA & NA \\
\hline Cardiac, n (\%) & $20(10.7)$ & $17(2.3)$ & $1(0.6)$ & $0(0.0)$ & $5(4.0 \%)$ & $1 \%$ \\
\hline Renal, $n(\%)$ & $2(1.1)$ & $5(0.7)$ & $4(2.4)$ & $0(0.0)$ & NA & $3 \%$ \\
\hline Bone/joint, $n$ (\%) & $18(9.6)$ & $4(0.5)$ & $6(3.6)$ & $0(0.0)$ & NA & $12 \%$ \\
\hline Muscle, $n(\%)$ & $2(1.1)$ & $3(0.4)$ & $0(0.0)$ & $0(0.0)$ & NA & NA \\
\hline
\end{tabular}

ENT ear, nose, and throat, UMN University of Minnesota, ACCESS A Case Control Etiologic Study of Sarcoidosis, UCSF University of California San Francisco ${ }^{a}$ Age at diagnosis

${ }^{\mathrm{b}}$ Age at visit

Including erythema nodosum

Olmsted County in Minnesota [25] had fewer cases with eye involvement, but more bone and joint disease. In our cohort, in addition to higher proportion of extra-thoracic lymph node, eye, liver, spleen, and bone-joint involvement, cardiac sarcoidosis, a high-risk manifestation of sarcoidosis, was also more frequent. Given the interaction between the environmental factors and genetics in the pathogenesis of sarcoidosis, regional variations in disease phenotypes may be due to differences in the genetics of the population and/or the nature of the exposure(s) triggering the disease. Because our cohort is drawn from a referral center for sarcoidosis, there may be enrichment for more complicated and advanced cases.

Pulmonary sarcoidosis continues to result in significant morbidity and mortality with rising death rates [10], hospital admissions, and health care costs [2]. It is associated with significantly reduced health related quality of life and symptoms portending the need for treatment and for disease progression [26]. A large proportion of our cases were either stage II/III disease or stage 0 disease, and stage IV primarily fibrotic disease is less common. A substantial proportion of our cases had near normal spirometry and DLCO, and restrictive ventilatory defect was the most frequent finding on pulmonary function testing compared to obstructive and mixed patterns. A large proportion of subjects in our cohort required treatment with anti-inflammatory agents. In the ACCESS incident cohort, lung function was normal in many with FVC $>80 \%$ in $69 \%$, yet $\sim 47 \%$ cases had Scadding stage II/III disease while stage IV disease was present in only $\sim 5 \%$. In our cohort, the median and 25 th percentile of FVC is $88 \%$ predicted and $72 \%$ predicted, findings similar to ACCESS. Similar results were also seen for FEV1, and obstructive changes were common with an FEV1/FVC ratio of $<70 \%$ in more than 
$20 \%$ of patients. An isolated gas exchange abnormality is not uncommon in sarcoidosis and thus an important clinical outcome. In our cohort, $14.0 \%$ had an abnormal DLCO and normal TLC, while 6.6\% had abnormal DLCO and normal spirometry, and 17\% demonstrated normal DLCO and abnormal spirometry. Thus, patients may demonstrate obstructive, restrictive, mixed patterns or an isolated DLCO. Researchers have commonly used spirometry, DLCO, and chest radiography, to track disease progression in studies [27, 28]. Lung volumes or formal cardiopulmonary exercise testing (CPET) is not routinely used nor is a standard of care in sarcoidosis clinical practice or research as it is more invasive, expensive and normal in many [29]. Patient-reported outcome measures and the six-minute walk test have been recommended in disease assessment [30]. A recent international Delphi study supported multi-faceted outcomes to assess disease severity for clinical and research purposes, including spirometry/DLCO, quality of life, assessment of progression as well as a biomarker [31]. These data support the importance of defining a comprehensive biomarker of disease progression.

A recent NHLBI workshop recognized cardiac involvement as a high-risk phenotype [12, 32]. The proportion of sarcoidosis cases with abnormal advanced cardiac imaging was substantially higher in our cohort than the ACCESS and other cohorts (Table 9), but less than the reported incidence in post mortem studies [33-35]. Similar rates of increased detection of cardiac sarcoidosis has also been reported by other investigators employing contemporary imaging studies [36-38]. The utility of these imaging modalities is now widely recognized and incorporated in the diagnostic criteria for cardiac sarcoidosis. The ACCESS criteria did not have advanced imaging criteria, and for the 2006 Japanese Ministry of Health and Welfare (JMHW) criteria, late gadolinium enhancement (LGE) on cardiac MRI was a minor criterion [39] and needed additional criteria to be fulfilled for a diagnosis of cardiac sarcoidosis. In contrast, in the current recommendations by Heart Rhythm Society (HRS), LGE on CMR is sufficient for an adequate clinical diagnosis of cardiac disease in the presence of histologic extracardiac evidence of sarcoidosis [40]. Similarly, for the WASOG organ assessment tool that we used for this cohort [18] and the Japanese Circulation Society Guidelines [41], LGE on cardiac MRI makes the likelihood of cardiac involvement at least probable. Similarly, patchy uptake on a dedicated cardiac PET scan has also been incorporated into the HRS and the WASOG criteria. A crucial element in establishing a diagnosis of cardiac sarcoidosis, even with histology proven extra-cardiac disease, is excluding other causes of LGE, such as coronary artery disease or other non-ischemic cardiomyopathies such as genetic arrhythmogenic cardiomyopathies which could also demonstrate increased myocardial uptake on FDG-PET imaging [42]. Challenges also remain regarding the ideal dietary preparation to suppress normal glucose uptake by the myocardium and avoid false positive FDG-PET. A diffuse uptake of FDG is suggestive of incomplete suppression of physiological glucose uptake in contrast to a patchy or patchy on diffuse uptake that may suggest myocardial inflammatory process [43, 44]. In the absence of a gold standard, as suggested by other groups [45], a multidisciplinary approach is likely to improve the accuracy of diagnosis. The long-term outcomes of cases with abnormal cardiac imaging, especially in cases with no or minimal symptoms and normal heart function, remains unknown.

Extra-pulmonary involvement is presumed to be more common in blacks with sarcoidosis. However despite being a cohort composing of predominantly white cases, our cohort had frequent multisystem disease (using the GRADS criteria and also the WASOG organ assessment tool). We observed more frequent involvement of the skin, extra thoracic lymph nodes, liver, spleen, neurologic, cardiac and bone and joint disease. Of these, neurologic, cardiac, and multisystem disease were considered high-risk manifestations of sarcoidosis due to higher morbidity and mortality. Bone and joint involvement is also a frequent cause of impaired quality of life and often requires systemic anti-inflammatory therapy. We included cases with Lofgren's syndrome in this category due to our observation of significant morbidity during the acute presentation related to arthralgias, although most of these cases had improvement in symptoms and did not need chronic therapy. As the size of our cohort grows, it will be ideally suited for future studies of high-risk sarcoidosis phenotypes.

We also examined laboratory studies obtained at the clinic visits. Routine laboratory tests were performed for surveillance of drug-related side effects to assess the disease activity with biomarkers and for asymptomatic organ involvement [46]. We identified differences in several analytes in the treated vs. untreated groups and in blacks compared to whites. A higher leukocyte count in treated sarcoidosis cases could reflect an appropriate response to therapy including improved hematopoiesis [47]. Leukopenia as a manifestation of sarcoidosis could be due to bone marrow involvement $[48,49]$, hypersplenism [50], or lymphocyte redistribution. The $\mathrm{T}$ cell redistribution is reported to cause peripheral lymphopenia and is linked to worse severity of the sarcoidosis [51, 52]. We did not observe any difference in the lymphocyte count in the treated vs. untreated and blacks vs. whites. Our cohort is larger in size than the cohort where peripheral lymphopenia was observed and has a larger proportion of cases with lung involvement [52]. Other potential biomarkers of disease activity such as angiotensin converting enzyme $[53,54]$ and soluble IL-2R 
levels $[55,56]$ were also not different in treated vs untreated groups or in whites vs. blacks. The higher level of albumin observed in whites and a higher level of total protein in blacks has been reported previously [57] in these racial groups. Difference in protein fractional patterns could explain a higher IgG level. Various reasons including frequent infections or persistent chronic inflammation could account for the differences in albumin and immunoglobulin levels $[58,59]$. Overall, these findings are in line with the findings of other reports that current biomarkers have limited utility for assessing disease activity in sarcoidosis, and highlight the urgent need to develop biomarkers for prognostication and measuring response to therapy [32]. Concurrent to the search for useful serum biomarkers for disease activity, methods for incorporating comprehensive data including other assessments of disease activity, extent of organ dysfunction, and patient reported outcomes, are needed to improve disease severity assessment, prognosis assessment, and guidelines for treatment.

We observed a high proportion of cases that needed systemic anti-inflammatory therapy. Oral corticosteroids are the first-line agents with methotrexate and Imuran as the preferred steroid sparing agent. The dosing of TNF blockers used in sarcoidosis at our center is different than the typical dose for rheumatologic conditions with a maintenance dose of every four weeks $(5 \mathrm{mg} / \mathrm{kg})$ for infliximab, in line with the current experience-based recommendations [60].

Despite the retrospective nature of our study, this cohort description provides new insights into regional variability of sarcoidosis as it represents the clinical manifestation in residents of the upper Midwest. Our cohort is a mixed population of incident and prevalent cases and might be a more appropriate representation of sarcoid-related morbidity as opposed to a cohort of newly diagnosed cases. For assessment of pulmonary function testing, we used percent predicted values to assess lung function abnormalities. The other option of using percentile cutoff might be more appropriate, but we do not have this information on all the participants in our study. We also acknowledge that not all the cases in our cohort had all the data points that we presented. As our cohort size grows, we expect the missing values to have a lesser impact on the study findings.

\section{Conclusion}

Among sarcoidosis cases in our predominantly white Minnesota population, we found a relatively high proportion of advanced and multisystem disease. Lofgren's syndrome was not common in our cohort despite high percentage of presumed north-European ancestry in our population. Stage II/III pulmonary disease, cardiac disease, multisystem diseases and joint and bone diseases are more frequently detected in this cohort. The analysis of our cohort highlights the lack of utility of serum biomarkers and limitations of pulmonary function tests in assessing prognosis, need for treatment, and disease severity. The higher incidence of cardiac disease, compared to previous cohorts, suggests that cardiac involvement may be under-recognized and highlights the importance of incorporating advanced imaging and a multidisciplinary approach into the evaluation of patients suspected of cardiac involvement. Our cohort is well suited to investigate high-risk sarcoidosis phenotypes, and studying regional variations in disease phenotypes may shed light on disease mechanisms. Incorporating patient reported outcomes in routine care could provide additional insights into indications and outcomes of treatment.

\section{Abbreviations}

ACE: Angiotensin converting enzyme; ACCESS: A Case Control Etiologic Study of Sarcoidosis; ATS: American Thoracic Society; CBD: Chronic beryllium disease; CPET: Cardiac -positron emission tomography; CVID: Common variable immunoglobulin deficiency; DLCO: Diffusing capacity of the lungs for carbon monoxide; FDG: Fluorodeoxyglucose; FEV1: Forced expiratory volume in $1 \mathrm{~s}$; FVC: Forced vital capacity; GRADS: Genomic Research in Alpha-1 Antitrypsin Deficiency and Sarcoidosis; HRS: Heart Rhythm Society; JMHW: Japanese Ministry of Health and Welfare; LGE: Late gadolinium enhancement; NASH: Nonalcoholic steatohepatitis; sIL-2R: Soluble interleukin 2 receptor; TLC: Total lung capacity; UCSF: University of California San Francisco; UMN: University of Minnesota; WASOG: World Association of Sarcoidosis and Other Granulomatous Disorders; WBC: White blood cell

\section{Acknowledgements}

Not applicable.

\section{Authors' contributions}

HST: data abstraction, statistical analysis, manuscript development and editing. DMP: subject recruitment, data interpretation, study design, manuscript development. CS: cardiac MRI interpretation, study design, manuscript development and editing. DJS: cardiac PET interpretation, manuscript editing. RJC: subject recruitment for cardiac sarcoidosis, manuscript editing. HR: cardiac electrophysiology data interpretation, manuscript editing. LZ: statistical analysis, manuscript editing. TLA: interpretation of radiology imaging, Scadding staging, manuscript development and editing. EJP: manuscript development and editing. MB: subject recruitment, data analysis, data interpretation, manuscripts development, manuscript editing, study design. All authors have read and approved the manuscript.

\section{Funding}

Sarcoidosis Research and Education Foundation for providing funding for research infrastructure at the Center of Lung Health and Science, Division of Pulmonary, Allergy, Critical Care and Sleep Medicine and Department of Medicine for financial support to MB.

\section{Availability of data and materials}

The datasets generated during and/or analyzed during the current study are not publicly available due to HIPPA regulations and are available from the corresponding author on reasonable request.

\section{Ethics approval and consent to participate}

The study was approved by University of Minnesota Institutional Review Board with protocol number 1501 M60321 for collection of biospecimens and clinical data.

\section{Consent for publication}

Not applicable.

Competing interests

The authors declare that they have no competing interests. 


\section{Author details}

'Division of Pulmonary, Allergy, Critical Care and Sleep Medicine, Department of Medicine, Univesity of Minnesota Medical School, Minneapolis, USA. ${ }^{2}$ Cardivascular Division, Department of Medicine, Univesity of Minnesota Medical School, Minneapolis, USA. ${ }^{3}$ Division of Rheumatic and Autoimmune Diseases, Department of Medicine, University of Minnesota Medical School, Minneapolis, MN, USA. ${ }^{4}$ Department of Radiology, University of Minnesota Medical School, Minneapolis, USA. ${ }^{5}$ Division of Biostatistics, School of Public Health, University of Minnesota, Minneapolis, MN, USA.

\section{Received: 7 November 2019 Accepted: 19 May 2020} Published online: 01 June 2020

\section{References}

1. Statement on sarcoidosis. Joint Statement of the American Thoracic Society (ATS), the European Respiratory Society (ERS) and the World Association of Sarcoidosis and Other Granulomatous Disorders (WASOG) adopted by the ATS Board of Directors and by the ERS Executive Committee, February 1999. Am J Respir Crit Care Med. 1999;160(2):736-55.

2. Gerke AK. Morbidity and mortality in sarcoidosis. Curr Opin Pulm Med. 2014 20(5):472-8

3. Gerke AK, Judson MA, Cozier YC, Culver DA, Koth LL. Disease Burden and Variability in Sarcoidosis. Ann Am Thorac Soc. 2017; 14(Supplement_6):S421-8.

4. Valeyre D, Prasse A, Nunes H, Uzunhan Y, Brillet PY, Muller-Quernheim J. Sarcoidosis. Lancet. 2014:383(9923):1155-67.

5. Erdal BS, Clymer BD, Yildiz VO, Julian MW, Crouser ED. Unexpectedly high prevalence of sarcoidosis in a representative U.S. metropolitan population. Respir Med. 2012;106(6):893-9.

6. Newman LS, Rose CS, Maier LA. Sarcoidosis. N Engl J Med. 1997;336(17): 1224-34

7. Rybicki BA, Major M, Popovich J Jr, Maliarik MJ, lannuzzi MC. Racial differences in sarcoidosis incidence: a 5-year study in a health maintenance organization. Am J Epidemiol. 1997;145(3):234-41.

8. Iannuzzi MC, Rybicki BA, Teirstein AS. Sarcoidosis. N Engl J Med. 2007; 357(21):2153-65.

9. Mirsaeidi M, Machado RF, Schraufnagel D, Sweiss NJ, Baughman RP. Racial difference in sarcoidosis mortality in the United States. Chest. 2015;147(2): 438-49.

10. Swigris JJ, Olson AL, Huie TJ, Fernandez-Perez ER, Solomon J, Sprunger D, Brown KK. Sarcoidosis-related mortality in the United States from 1988 to 2007. Am J Respir Crit Care Med. 2011;183(11):1524-30.

11. Baughman RP, Teirstein AS, Judson MA, Rossman MD, Yeager H Jr, Bresnitz EA, DePalo L, Hunninghake G, lannuzzi MC, Johns CJ, et al. Clinical characteristics of patients in a case control study of sarcoidosis. Am J Respir Crit Care Med. 2001:164(10 Pt 1):1885-9.

12. Sauer WH, Stern BJ, Baughman R, Culver DA, Royal W. High risk Sarcoidosis: current concepts and research imperatives. Ann Am Thorac Soc. 2017;14 (Supplement_6):S437-S444.

13. Iwai $K$, Sekiguti M, Hosoda Y, DeRemee RA, Tazelaar HD, Sharma OP, Maheshwari A, Noguchi TI. Racial difference in cardiac sarcoidosis incidence observed at autopsy. Sarcoidosis. 1994;11(1):26-31.

14. Brown F, Tanner LS. Lofgren Syndrome. In StatPearls [Internet]. Treasure Island (FL): StatPearls Publishing; 2020. PMID: 29493940

15. Judson MA, Baughman RP, Teirstein AS, Terrin ML, Yeager H Jr. Defining organ involvement in sarcoidosis: the ACCESS proposed instrument ACCESS research group. A Case control etiologic study of Sarcoidosis. Sarcoidosis Vasc Diffuse Lung Dis. 1999;16(1):75-86.

16. Carrillo-Perez DL, Apodaca-Chaveza El, Carrillo-Maravilla E, Mejia-Avila M, Hernandez-Oropeza JL, Reyes E, Atisha-Fregoso Y, Hernandez-Molina G. Sarcoidosis: a single hospital-based study in a 24-year period. Rev Investig Clin. 2015;67(1):33-8

17. Markevitz N, Epstein Shochet G, Levi Y, Israeli-Shani L, Shitrit D. Sarcoidosis in Israel: clinical outcome status, organ involvement, and long-term followup. Lung. 2017;195(4):419-24.

18. Judson MA, Costabel U, Drent M, Wells A, Maier L, Koth L, Shigemitsu H, Culver DA, Gelfand J, Valeyre D, et al. The WASOG Sarcoidosis organ assessment instrument: an update of a previous clinical tool. Sarcoidosis Vasc Diffuse Lung Dis. 2014;31(1):19-27.

19. Moller DR, Koth LL, Maier LA, Morris A, Drake W Rossman M, Leader JK, Collman RG, Hamzeh N, Sweiss NJ, et al. Rationale and Design of the Genomic Research in Alpha-1 antitrypsin deficiency and Sarcoidosis (GRADS) study. Sarcoidosis Protocol. Ann Am Thorac Soc. 2015;12(10):1561-71.

20. Minnesota Population 2019. https://data.census.gov/cedsci/table?g=01 00000US_0400000US27\&tid=ACSDT5Y2017.B04006\&q=B04006.

21. 2013-2017 American Community Survey 5-Year Estimates. In.: US Census Bureau; 2017. (data.census.gov).

22. Vogelmeier CF, Criner GJ, Martinez FJ, Anzueto A, Barnes PJ, Bourbeau J, Celli BR, Chen R, Decramer M, Fabbri LM, et al. Global Strategy for the Diagnosis, Management, and Prevention of Chronic Obstructive Lung Disease 2017 Report. GOLD executive summary. Am J Respir Crit Care Med. 2017;195(5):557-82.

23. Kazmirczak F, Chen KA, Adabag S, von Wald L, Roukoz H, Benditt DG, Okasha O, Farzaneh-Far A, Markowitz J, Nijjar PS, et al. Assessment of the 2017 AHA/ACC/HRS guideline recommendations for implantable Cardioverter-defibrillator implantation in cardiac Sarcoidosis. Circ Arrhythm Electrophysiol. 2019;12(9):e007488.

24. Ungprasert P, Crowson CS, Matteson EL. Epidemiology and clinical characteristics of sarcoidosis: an update from a population-based cohort study from Olmsted County, Minnesota. Reumatismo. 2017;69(1):16-22.

25. Benn BS, Lehman Z, Kidd SA, Ho M, Sun S, Ramstein J, Arger NK, Nguyen CP, Su R, Gomez A, et al. Clinical and biological insights from the University of California san Francisco prospective and longitudinal cohort. Lung. 2017; 195(5):553-61.

26. Judson MA, Preston S, Hu K, Zhang R, Jou S, Modi A, Sukhu I, llyas F, Rosoklija G, Yucel R. Quantifying the relationship between symptoms at presentation and the prognosis of sarcoidosis. Respir Med. 2019;152:14-9.

27. Su R, Li MM, Bhakta NR, Solberg OD, Darnell EP, Ramstein J, Garudadri S, Ho M, Woodruff PG, Koth LL. Longitudinal analysis of sarcoidosis blood transcriptomic signatures and disease outcomes. Eur Respir J. 2014;44(4): 985-93.

28. Arger NK, Ho M, Woodruff PG, Koth LL. Serum CXCL11 correlates with pulmonary outcomes and disease burden in sarcoidosis. Respir Med. 2019, 152:89-96.

29. Chenivesse C, Boulanger S, Langlois C, Wemeau-Stervinou L, Perez T, Wallaert B. Oxygen desaturation during a 6-minute walk test as a predictor of maximal exercise-induced gas exchange abnormalities in sarcoidosis. J Thorac Dis. 2016:8(8):1995-2003.

30. Baughman RP, Sparkman BK, Lower EE. Six-minute walk test and health status assessment in sarcoidosis. Chest. 2007:132(1):207-13.

31. Kampstra NA, Grutters JC, van Beek FT, Culver DA, Baughman RP, Renzoni EA, Wuyts W, Kouranos V, Wijsenbeek MS, Biesma DH, et al. First patientcentred set of outcomes for pulmonary sarcoidosis: a multicentre initiative. BMJ Open Respir Res. 2019;6(1):e000394.

32. Maier LA, Crouser ED, Martin WJ, Eu J: Executive summary of the NHLBI Workshop Report: Leveraging Current Scientific Advances to Better Understand Sarcoidosis Variability and Improve Outcomes. Ann Am Thorac Soc 2017.

33. Matsui $Y$, Iwai $K$, Tachibana $T$, Fruie $T$, Shigematsu N, Izumi T, Homma AH, Mikami R, Hongo O, Hiraga Y, et al. Clinicopathological study of fatal myocardial sarcoidosis. Ann N Y Acad Sci. 1976;278:455-69.

34. Roberts WC, MCAllister HA Jr, Ferrans VJ. Sarcoidosis of the heart. A clinicopathologic study of 35 necropsy patients (group 1) and review of 78 previously described necropsy patients (group 11). Am J Med. 1977;63(1): 86-108.

35. Silverman KJ, Hutchins GM, Bulkley BH. Cardiac sarcoid: a clinicopathologic study of 84 unselected patients with systemic sarcoidosis. Circulation. 1978; 58(6):1204-11.

36. Patel AR, Klein MR, Chandra S, Spencer KT, Decara JM, Lang RM, Burke MC, Garrity ER, Hogarth DK, Archer SL, et al. Myocardial damage in patients with sarcoidosis and preserved left ventricular systolic function: an observational study. Eur J Heart Fail. 2011;13(11):1231-7.

37. Patel AR, Kramer CM. Role of Cardiac Magnetic Resonance in the Diagnosis and Prognosis of Nonischemic Cardiomyopathy. JACC Cardiovasc Imaging. 2017:10(10 Pt A):1180-93.

38. Patel MR, Cawley PJ, Heitner JF, Klem I, Parker MA, Jaroudi WA, Meine TJ, White JB, Elliott MD, Kim HW, et al. Detection of myocardial damage in patients with sarcoidosis. Circulation. 2009;120(20):1969-77.

39. Soejima K, Yada H. The work-up and management of patients with apparent or subclinical cardiac sarcoidosis: with emphasis on the associated heart rhythm abnormalities. J Cardiovasc Electrophysiol. 2009; 20(5):578-83. 
40. Birnie DH, Sauer WH, Bogun F, Cooper JM, Culver DA, Duvernoy CS, Judson MA, Kron J, Mehta D, Cosedis Nielsen J, et al. HRS expert consensus statement on the diagnosis and management of arrhythmias associated with cardiac sarcoidosis. Heart Rhythm. 2014;11(7):1305-23.

41. Fumio Terasaki KY. New guidelines for diagnosis of cardiac Sarcoidosis in Japan. Ann Nucl Cardiol. 2017.

42. Okasha O, Kazmirczak F, Chen KA, Farzaneh-Far A, Shenoy C. Myocardial involvement in patients with histologically diagnosed cardiac Sarcoidosis: a systematic review and meta-analysis of gross pathological images from autopsy or cardiac transplantation cases. J Am Heart Assoc. 2019;8(10): e011253.

43. Cerqueira M, Case J, Maddahi J. Proceedings of the ASNC cardiac PET summit meeting, May 12, 2014, Baltimore MD : 5. Advances in radiopharmaceutical availability and development of cardiac PET tracers. J Nucl Cardiol. 2015:22(4):730-9.

44. Slart R, Glaudemans A, Lancellotti P, Hyafil F, Blankstein R, Schwartz RG, Jaber WA, Russell R, Gimelli A, Rouzet F, et al. A joint procedural position statement on imaging in cardiac sarcoidosis: from the cardiovascular and Inflammation \& Infection Committees of the European Association of Nuclear Medicine, the European Association of Cardiovascular Imaging, and the American society of nuclear cardiology. J Nucl Cardiol. 2017.

45. Ribeiro Neto ML, Jellis $C L$, Joyce E, Callahan TD, Hachamovitch R, Culver DA. Update on Cardiac Sarcoidosis. Ann Am Thorac Soc. 2019.

46. Judson MA. The three tiers of screening for sarcoidosis organ involvement. Respir Med. 2016;113:42-9.

47. Pena-Garcia Jl, Shaikh S, Barakoti B, Papageorgiou C, Lacasse A. Bone marrow involvement in sarcoidosis: an elusive extrapulmonary manifestation. J Community Hosp Intern Med Perspect. 2019;9(2):150-4.

48. Yanardag H, Pamuk GE, Karayel T, Demirci S. Bone marrow involvement in sarcoidosis: an analysis of 50 bone marrow samples. Haematologia (Budap). 2002;32(4):419-25.

49. Pease GL. Granulomatous lesions in bone marrow. Blood. 1956;11(8):720-34.

50. Pavlovic-Popovic Z, Zaric B, Kosjerina Z, Petrovic D. Splenomegaly in Sarcoidosis: frequency, treatment, prognosis and long-term follow-up. Srp Arh Celok Lek. 2015;143(5-6):279-83.

51. Jones NP, Tsierkezou L, Patton N. Lymphopenia as a predictor of sarcoidosis in patients with uveitis. Br J Ophthalmol. 2016;100(10):1393-6.

52. Sweiss NJ, Salloum R, Gandhi S, Alegre ML, Sawaqed R, Badaracco M, Pursell K, Pitrak D, Baughman RP, Moller DR, et al. Significant CD4, CD8, and CD19 lymphopenia in peripheral blood of sarcoidosis patients correlates with severe disease manifestations. PLoS One. 2010;5(2):e9088.

53. Duan J, Xu Y, Zhu H, Zhang H, Sun S, Sun H, Wang W, Xie S. Relationship between $\mathrm{CT}$ activity score with lung function and the serum angiotensin converting enzyme in pulmonary sarcoidosis on chest HRCT. Medicine (Baltimore). 2018;97(36):e12205.

54. Ungprasert P, Carmona EM, Crowson CS, Matteson EL. Diagnostic utility of angiotensin-converting enzyme in Sarcoidosis: a population-based study. Lung. 2016;194(1):91-5.

55. Ziegenhagen MW, Benner UK, Zissel G, Zabel P, Schlaak M, MullerQuernheim J. Sarcoidosis: TNF-alpha release from alveolar macrophages and serum level of sIL-2R are prognostic markers. Am J Respir Crit Care Med. 1997:156(5):1586-92.

56. Miyoshi S, Hamada H, Kadowaki T, Hamaguchi N, Ito R, lrifune K, Higaki J. Comparative evaluation of serum markers in pulmonary sarcoidosis. Chest. 2010;137(6):1391-7.

57. Koh ET, Chi MS, Lowenstein FW. Comparison of selected blood components by race, sex, and age. Am J Clin Nutr. 1980;33(8):1828-35.

58. Lichtman MA, Hames CG, McDonough JR. Serum protein electrophoretic fractions among negro and White subject in Evans County, Georgia. Am J Clin Nutr. 1965;16:492-508.

59. Lichtman MA, Vaughan JH, Hames CG. The distribution of serum immunoglobulins, anti-gamma-G globulins ("rheumatoid factors") and antinuclear antibodies in White and negro subjects in Evans County. Georgia. Arthritis Rheum. 1967;10(3):204-15.

60. Drent M, Cremers JP, Jansen TL, Baughman RP. Practical eminence and experience-based recommendations for use of TNF-alpha inhibitors in sarcoidosis. Sarcoidosis Vasc Diffuse Lung Dis. 2014;31(2):91-107.

\section{Publisher's Note}

Springer Nature remains neutral with regard to jurisdictional claims in published maps and institutional affiliations.

\section{Ready to submit your research? Choose BMC and benefit from}

- fast, convenient online submission

- thorough peer review by experienced researchers in your field

- rapid publication on acceptance

- support for research data, including large and complex data types

- gold Open Access which fosters wider collaboration and increased citations

- maximum visibility for your research: over $100 \mathrm{M}$ website views per year

At $\mathrm{BMC}$, research is always in progress.

Learn more biomedcentral.com/submissions 